\title{
La Directiva de Retorno de la Unión Europea: apuntes críticos desde una perspectiva de derechos humanos*
}

Este comentario, junto a los documentos que analiza, está disponible en www.anuariocdh.uchile.cl

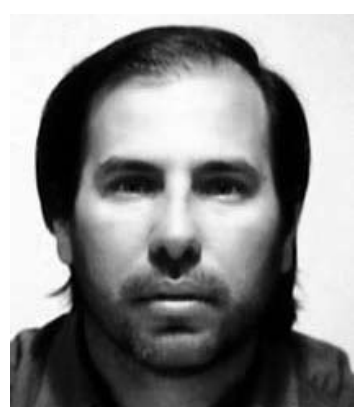

\author{
Pablo Ceriani Cernadas
}

Abogado, Universidad de Buenos Aires. Doctorando en Derechos Fundamentales, Universidad de Valencia (tema de tesis: Derechos humanos y políticas migratorias en América Latina). Profesor de la Maestría en Derechos Humanos Universidad Nacional de Lanús (UNLa). Investigador del Centro de Derechos Humanos de la UNLa, Buenos Aires, Argentina.

pablo.c1eriani@uv.es

\section{RESUMEN}

Este trabajo examina, desde la perspectiva de los derechos humanos, el contenido de la Directiva de Retorno de Inmigrantes aprobada por la Unión Europea en 2008. En particular, se trata de una observación crítica a los aspectos más cuestionables de una regulación que, en busca de pautas comunes mínimas en materia de sanción de la migración irregular, genera una preocupante regresividad respecto de principios fundamentales del derecho internacional de los derechos humanos. Entre los temas más conflictivos destaca la detención prolongada, la privación de libertad de niños, la ausencia de medidas alternativas a la detención, la expulsión y su impacto en el derecho a la vida familiar, la expulsión de niños, la ausencia de garantías esenciales en esos procedimientos y la inaplicación de la escasa protección que brinda la Directiva en ciertas circunstancias. Finalmente, se destaca cómo este nuevo marco jurídico profundiza la política migratoria que viene adoptando la UE en los últimos años, centrada en una lógica de control y persecución de la migración irregular, que afecta el pleno respeto y garantía sin discriminación alguna de los derechos humanos a todas las personas, sin perjuicio de su nacionalidad o condición migratoria.

\section{Introducción}

En diversas regiones del mundo asistimos a una creciente disputa entre las normas y políticas diseñadas por numerosos países para controlar la migración y regular los derechos de las personas migrantes y los cuestionamientos a esas políticas por vulnerar principios del Derecho Internacional de los Derechos Humanos (DIDH). En este contexto, la Unión Europea adoptó la Directiva sobre los procedimientos y normas comunes en los Estados miembros para el retorno de nacionales de terceros países que se encuentren ilegalmente en su territorio ${ }^{1}$.

\footnotetext{
* El autor agradece los aportes y comentarios sustanciales efectuados por Leonardo Franco, Víctor Abramovich, Ricardo Fava y Diego Morales.

1 Directiva 2008/115/CE del Parlamento Europeo y del Consejo, del 16/12/2008, publicada en el Diario Oficial de la Unión Europea del 24/12/2008. La Directiva había sido aprobada por el Parlamento el 18/06/08 y por el Consejo el 09/12/08.
} 
La Directiva ha generado múltiples reacciones: organizaciones sociales, académicos e incluso Estados de otras regiones han manifestado su oposición o disconformidad. La Comisión Interamericana de Derechos Humanos expresó que la Directiva suscita serias preocupaciones, especialmente por la ausencia de garantías suficientes para los migrantes y solicitantes de asilo ${ }^{2}$. La Directiva representa un peldaño más en el diseño de la política inmigratoria europea, la cual tiene entre sus ejes centrales el control y la sanción de la migración irregular. Los dispositivos elaborados por la Unión Europea (UE) para controlar la inmigración de otras regiones y regular las condiciones de su permanencia ${ }^{3}$ han generado derechos desiguales entre personas que habitan un mismo territorio en base a su nacionalidad o estatus migratorio ${ }^{4}$.

La posición de la UE sobre la migración irregular en la Directiva se evidencia con el uso de la terminología inmigrantes "ilegales" e iniciativas orientadas a "la lucha contra la inmigración ilegal". El uso reiterado en la política de la UE respecto de los países de origen y tránsito de migrantes ${ }^{5}$ del concepto "ilegal" ha sido cuestionado por numerosos actores sociales y políticos, inclusive el propio Consejo de Europa ${ }^{6}$. La migración irregular es un fenómeno complejo que exige una solución diferente a su persecución o "lucha": debe atenderse seriamente a las causas de la migración de millones de personas, las condiciones en que se realiza y a la vulnerabilidad de esas circunstancias antes de criminalizar sus consecuencias.

Este breve comentario examinará algunos componentes de la Directiva, especialmente aquellos que implican ciertas contradicciones con normas y principios internacionales. Para ello, veremos informes de instituciones europeas (ONGs, el Consejo de Europa o la propia UE) que la contradicen o cuestionan, y analizaremos las reacciones que generó en organismos intergubernamentales, entidades sociales y gobiernos sudamericanos. En este último caso, señalaremos sucintamente las cuestiones pendientes en las políticas migratorias en Sudamérica.

\section{La Directiva y los derechos humanos: principales preocupaciones}

Las preocupaciones centrales que surgen de la Directiva están agrupadas en tres materias: la expulsión de migrantes, la detención y las circunstancias en que los Estados pueden dejar sin aplicación las garantías establecidas en esta norma.

\section{a. Expulsión y detención: precisiones terminológicas}

Los conceptos utilizados por la Directiva no se corresponden fielmente con las materias que regula. Aunque alude al término "retorno", hubiera sido más ajustado a la realidad y a sus objetivos referirse a la expulsión. Si bien la norma distingue (ambiguamente) ambas medidas, una de las metas principales de la Directiva es diseñar pautas comunes para la expulsión forzosa de migrantes, no su retorno voluntario. Además, resulta difícil, si no imposible, que las personas acepten salir del

$2 \mathrm{CIDH}$. Derechos Humanos de Migrantes, Estándares Internacionales y la Directiva de Retorno de la UE. Resolución $N^{\circ} 03 / 08$.

3 Para un mayor análisis sobre la política migratoria de la UE, véase, junto a la bibliografía citada en estas páginas, SOLANES, A. La política de inmigración en la Unión Europea. Desde tres claves. Revista ARBOR. Ciencia, Pensamiento y Cultura. (713): 81-100, 2005.

4 Balibar ha asociado estas prácticas con un sistema de apartheid. BALIBAR, E. Nosotros, ¿Ciudadanos de Europa? Madrid, Tecnos, 2003, pp. 191, 192.

5 DE LUCAS, J. Cómo introducir el principio de justicia en las políticas de inmigración. En: MIRAUT MARTíN, L. (ed.). Justicia, Migración y Derecho. Madrid, Dykinson, 2004, pp. 15-54, p. 24.

6 Asamblea Parlamentaria del Consejo de Europa. Human rights of irregular migrants. Resolución 1509, del 27/06/2006, párr. 7. 
país en que viven (y seguramente trabajan, con o sin autorización), considerando las dificultades, obstáculos o incluso abusos experimentados para migrar, el esfuerzo realizado o las diversas privaciones de derechos que pueden haber sufrido en el país que los quiere expulsar. Si la principal innovación de la Directiva no es el retorno voluntario, sino el mecanismo coercitivo de expulsión, ello debería haber quedado reflejado en el mismo nombre de la normativa.

Asimismo, la Directiva Ilama "internamiento" (artículos 15-18) a una circunstancia que, por su naturaleza jurídica, sus implicancias, las causas que la determinan o las condiciones de su ejecución, constituye una privación de libertad. El uso "eufemístico" de la terminología7 no sólo no oculta esa realidad sino que acrecienta las sospechas sobre las intenciones declaradas y los motivos reales de la Directiva. Clarificar esta cuestión facilita la identificación de los principios aplicables al examen sobre la adecuación y razonabilidad del "internamiento" a las obligaciones del Estado respecto del derecho a la libertad personal.

Por estas razones, sin perjuicio de la denominación (retorno, expulsión, internamiento o detención), lo relevante es la naturaleza jurídica y las consecuencias reales de cada medida.

\section{b. Expulsión de migrantes}

La expulsión de un inmigrante sin autorización de residencia supone la ejecución forzosa de la orden de salida del territorio (artículo 8). De este mecanismo y sus implicancias surgen diversas dudas y cuestionamientos. El análisis de estas implicancias debe responder a la necesidad de abordar con la debida profundidad -en múltiples escenarios- una impostergable discusión política, jurídica y social: la "gestión" de la inmigración irregular no puede tener como respuesta prioritaria la persecución y la sanción. Es urgente el diseño de modelos alternativos, que incluyan políticas de integración y regularización ${ }^{8}$, así como las causas estructurales de la migración.

\section{i. Expulsión y el derecho a la vida familiar}

Según el Consejo de Europa, el respeto del derecho a la vida familiar ${ }^{9}$ implica que no debería ejecutarse la expulsión de un inmigrante en situación irregular cuando tenga fuertes lazos familiares en el país. La Directiva no menciona este aspecto.

Las relaciones familiares sólo se invocan para una eventual prórroga del plazo de salida voluntaria (artículo 7). Ese aplazamiento, por "la existencia de niños escolarizados y [...] otros vínculos familiares y sociales", parecería habilitar, precisamente, la expulsión de personas con hijos y otros familiares en ese país ya que no implica la suspensión de la sanción, sino la mera prórroga del tiempo para abandonar el territorio. El artículo 14.1 alienta a respetar el principio de unidad familiar durante el plazo fijado para la salida, pero no para impedir su ejecución. Asimismo, la ausencia de la vida familiar como fundamento de concesión de un permiso de residencia (artículo 6.4) desconoce el reconocimiento de este derecho en diversos tratados de derechos humanos. Así, mientras no queda claro cómo satisfacer el artículo 5.b, que ordena a los Estados a tener en cuenta "la vida familiar", sí se evidencia la preeminencia de la expulsión (por una infracción administrativa) sobre el derecho a la vida familiar.

7 DE LUCAS, J. La UE ante la inmigración: balance de una esquizofrenia jurídica y política. En: CERIANI CERNADAS, P. y FAVA, R. (eds.). Políticas Migratorias y Derechos Humanos. Universidad Nacional de Lanús, en prensa, 2009.

8 El Global Migration Group (UNICEF, OIT, ACNUR, etc.) subrayó la ineficacia de las políticas de control migratorio para atender debidamente la migración irregular, siendo necesarias medidas "más constructivas", como la regularización migratoria. International Migration and Human Rights. 2008, p. 43).

9 Asamblea Parlamentaria del Consejo de Europa. Human rights of irregular migrants. Op. cit. nota 6, párr. 12.12. 


\section{ii. Expulsión y debido proceso}

La Directiva presenta diversas deficiencias en materia de garantías del debido proceso. Una garantía imprescindible en estos casos suele ser el derecho a un intérprete. Según la Directiva, los Estados "proporcionarán, previa petición, una traducción escrita u oral de los principales elementos de las decisiones de retorno[...], en una lengua que el nacional del tercer país comprenda o que pueda suponerse razonablemente que comprende" (artículo 12.2). Una serie de objeciones pueden efectuarse al respecto: primero, el deber de solicitar previamente el derecho de traducción podría legitimar cuestiones arbitrarias, por ejemplo, ¿cómo podría probar la persona que solicitó tal derecho y no se lo otorgaron? Segundo, la traducción puede ser oral, dificultando probar la corrección de esa interpretación, o su existencia. Tercero, se garantiza la traducción de "los principales elementos", lo que puede dar lugar a arbitrariedades y restar eficacia al derecho de defensa, garantía que pretende asegurarse. Cuarto, la traducción puede ser en una lengua que "supuestamente" comprende la persona: otra opción para la discrecionalidad y la pérdida de virtualidad del derecho de defensa y su garantía.

Asimismo, los Estados pueden no proporcionar esta traducción y la información sobre los recursos cuando se trate de personas que ingresaron irregularmente al territorio y no hayan obtenido luego un permiso para permanecer (basta un formulario tipo, artículo 12.3). Con este inciso, cuestionado por el $\mathrm{ACNUR}^{10}$, el ya acotado derecho al intérprete se desvanece para decenas de miles de personas (en situación de alta vulnerabilidad), y con él, el derecho de defensa, de acceso a la justicia y otros conexos en cada caso.

Por otra parte, la autoridad que resuelve el recurso puede ser judicial, administrativa u otra competente, con miembros imparciales e independientes (artículo 13). Así, una medida de expulsión podría confirmarse y ejecutarse sin intervención judicial, pese a su carácter punitivo y que afecta el pleno goce de numerosos derechos fundamentales ${ }^{11}$. Si bien la jurisprudencia del Tribunal Europeo no ha sido generosa respecto de las garantías en casos de expulsión de inmigrantes ${ }^{12}$, no puede derivarse de este hecho la negación del derecho a la justicia y el principio de control jurisdiccional.

La Directiva tampoco obliga expresamente a los Estados a garantizar el derecho a la asistencia jurídica gratuita. La persona "podrá" tener esos servicios, y los Estados "velarán" porque se concedan de forma gratuita, "previa solicitud" (artículo 13). Asimismo, el artículo 20 los autoriza a no brindar dicha gratuidad hasta un año después de su entrada en vigor, pese a ser un elemento medular del debido proceso en estas circunstancias. Esta "concesión" se vincula con las reticencias de algunos países a reconocer este derecho, especialmente por razones presupuestarias. Llama la atención que se prorrogue la ausencia de una garantía esencial, pero que al mismo tiempo se autorice la detención de los inmigrantes en situación irregular mientras no existan centros de detención dignos y destinados específicamente a estos efectos.

Luego, si la persona tiene un procedimiento pendiente (renovación de residencia u otro que le otorgue el derecho de estancia), el Estado "considerará" la posibilidad de suspender el retorno hasta que finalice dicho proceso (artículo 6.5). Este carácter casi suspensivo podría permitir expulsiones arbitrarias. Si la persona ha tenido una autorización para residir y solicitar su renovación,

10 UNHCR position on the proposal for a Directive on common standards and procedures in Member States for returning illegally staying third-country nationals. 16/06/2008.

11 Incluso, con doble sanción, pues el artículo 11 de la Directiva prevé una prohibición de reingreso de hasta 5 años.

12 Al respecto, véase CERIANI, P. Los derechos de los migrantes sin residencia legal en la jurisprudencia del Tribunal Europeo de Derechos Humanos: un balance complejo ante la realidad y los retos de la inmigración en la región. En: CERIANI, P. y FAVA, R. (eds.). Políticas Migratorias y Derechos Humanos. Op. cit., nota 7. 
parecería evidente que el Estado debería esperar que se resuelva dicha solicitud antes de ejecutar su expulsión. El Tribunal Europeo de Derechos Humanos (TEDH) ha subrayado que un recurso es efectivo contra una orden de expulsión (artículo 13 Convenio Europeo para la protección de los derechos humanos y las libertades fundamentales) si es idóneo de evitar su ejecución en caso que pueda vulnerar un derecho de manera potencialmente irreversible ${ }^{13}$. Asimismo, la salida del territorio con un expediente en trámite equivaldría, seguramente, a la afectación del debido proceso (administrativo y/o judicial), al no poder estar presente durante el proceso de decisión ${ }^{14}$. Ello, sin perjuicio de otros derechos vinculados a la solicitud de residencia (vida familiar, trabajo, integridad física, etc.), que se afectarían con el retorno, en muchos casos, irreparablemente.

Finalmente, si bien la Directiva reconoce el principio de no devolución, hubiera sido deseable, en el actual contexto de control migratorio hacia la UE, una referencia a la violación indirecta de tal principio. En el caso T.I. c. Reino Unido ${ }^{15}$, el TEDH sostuvo que el Estado que expulsa a una persona debe asegurarse que el Estado receptor no la remitirá a un tercer Estado si hay riesgo para su vida o integridad física. Esto es vital en el escenario presente. Algunos países africanos (como Marruecos, Libia o Mauritania) son países de origen, pero también de tránsito de migrantes desde otros países africanos hacia Europa, especialmente a España e Italia. Los operativos de retorno de numerosos migrantes, realizados por autoridades europeas en jurisdicción de esos países de tránsito, omiten evaluar una posible afectación indirecta del principio de no devolución.

\section{iii. Expulsión y derechos de niños}

La Directiva autoriza la "expulsión" de niños y niñas no acompañados (artículo 10), igual que a los adultos, como sanción por la condición migratoria, sin perjuicio de ciertas disposiciones para su protección (servicios apropiados, el interés superior del niño, garantizar su entrega a la familia, tutor o servicios adecuados). El Comité de Derechos del Niño, en su observación sobre el "trato de los menores no acompañados y separados de sus familias fuera de su país de origen" ${ }^{16}$, se refiere a un retorno voluntario y provisto de múltiples garantías (que exceden largamente las de la Directiva), pero no a la posibilidad de expulsión. Los 27 Estados de la UE han ratificado la Convención sobre Derechos del Niño.

El informe sobre los Centros de Internamiento en la UE ${ }^{17}$, elaborado a petición del Parlamento Europeo, subrayó que los niños nunca deberían ser retornados forzadamente. La Directiva omitió esta recomendación. Por ello, la Red Europea de Defensores de la Niñez destacó que el regreso de niños debe entenderse como "una reintegración en su entorno social de origen[...] a través de una repatriación asistida voluntaria y sólo si esta es considerada ser de sus mejores intereses, después de una cuidadosa evaluación incluyendo la debida atención de sus puntos de vista". Al contrario, la Directiva "no garantiza una reintegración, sino deja la repatriación como una tarea

13 TEDH. Caso Conka v. Bélgica. Demanda No 51564/99, del 05/02/2002, párr. 79.

14 También surgen una serie de interrogantes: ¿Qué ocurriría si ese trámite fuera resuelto positivamente? ¿El Estado procurará encontrar a la persona en su país de origen para notificarle la decisión y garantizar su reingreso a la UE? ¿Y si la expulsión le ocasionó la pérdida de su empleo, por el cual fue justamente autorizado a residir? Es difícil imaginar disposiciones similares en otros ámbitos del derecho, fuera de la inmigración, en algún Estado de la UE.

15 Demanda № 43844/98, decisión de admisibilidad, del 07/03/2000.

16 Comité de Derechos del Niño. Observación General № 6, Trato de los menores no acompañados y separados de sus familias fuera de su país de origen. 01/09/2005, CRC/GC/2005/6.

17 STEPS Consulting Social. The conditions in centres for third country national (detention camps, open centres as well as transit centres and transit zones) with a particular focus on provisions and facilities for persons with special needs in the 25 EU member states. Estudio encargado por el Parlamento Europeo, Bruselas, 12/2007, p. 21. 
de la policía[... $]^{\prime 18}$. La respuesta es en términos coercitivos y no está conforme con los estándares internacionales de protección integral de niños y niñas.

\section{c. Detención de migrantes}

El régimen de privación de libertad de la Directiva ha sido enérgicamente criticado ${ }^{19}$. La detención se prevé como medida cautelar "mientras se llevan a cabo las gestiones para la expulsión", en caso de acreditarse que "haya riesgo de fuga" o que la persona "evite o dificulte la preparación del proceso de retorno o expulsión" (artículo 15.1). Con ello, no podría disponerse una detención solo por la condición migratoria irregular, si no se verifica una de esas dos causales.

El riesgo de fuga o la obstrucción del proceso están vinculados al derecho procesal penal, en el cual la detención sólo es legítima cuando se utiliza como medida de ultima ratio y satisface todas las garantías procesales. En el caso de la Directiva estamos ante una detención por una infracción administrativa, cuya procedencia se resuelve por una autoridad administrativa o judicial (artículo 15.2$)^{20}$. Por ello, la detención debería ser aún más excepcional y debiese priorizarse cualquier otra medida alternativa. Sin embargo, el artículo 15.1 genera ciertas dudas sobre la prioridad de las medidas alternativas ${ }^{21}$, ya que parecería que prima la detención "salvo" que pudiera probarse la eficacia de otra medida ${ }^{22}$. En la Directiva este criterio, contrario al principio favor libertatis, se reafirma ante la ausencia de medidas alternativas a la detención que pudieran asegurar el retorno sin recurrir a la opción más gravosa.

\section{i. El plazo de detención}

La Directiva prevé un plazo de 6 meses de detención, prorrogable por otros 12 meses. De Lucas destaca la contradicción del Parlamento Europeo, que había cuestionado -meses antes de aprobar la Directiva- la duración de las detenciones de migrantes en Malta por un período máximo de 18 meses ${ }^{23}$. Igualmente, el informe sobre los centros de internamiento encargado por el Parlamento, recomendaba que el plazo debería fijarse en días y no en semanas o meses (la Directiva alcanza el año y medio $)^{24}$.

La posibilidad de adicionar 12 meses más al plazo de detención también es cuestionable por su justificación. La primera causal, "falta de cooperación" de la persona, controvierte el derecho a no declarar contra sí mismo. La segunda, "demoras en la documentación que deban expedir terceros países", afectaría principios centrales del DIDH, ya que un Estado restringiría un derecho fundamental por la actuación de otro Estado ${ }^{25}$.

18 European Network of Ombudspersons for Children (ENOC). Statement on the EU Return Directive of 18.06.2008, del 30-07-2008.

19 Así lo han hecho conjuntamente diez Relatores y Expertos de la ONU (UN experts express concern about proposed EU Return Directive, United Nations, Press Release, del 18/07/2008).

20 El Consejo de Europa subrayó que la detención de migrantes en situación irregular debe ser autorizada judicialmente. Asamblea Parlamentaria. Human rights of irregular migrants. Op. cit. nota 6, párr. 15.2.

21 "Salvo que en el caso concreto de que se trate puedan aplicarse con eficacia otras medidas suficientes de carácter menos coercitivo, los Estados miembros podrán mantener internados [...]".

22 Al contrario, el considerando 16 de la fundamentación de la Directiva dice: "Sólo se justifica el internamiento [...] si la aplicación de medidas menos coercitivas no es suficiente".

23 DE LUCAS, J. Op. cit. nota 7.

24 STEPS Consulting Social. Op. cit. nota 17, p. 21.

25 Según la Corte Interamericana los tratados de derechos humanos no son tratados multilaterales concluidos en función de un intercambio recíproco de derechos para el beneficio mutuo de los Estados contratantes. Su objeto y fin es la protección de los derechos fundamentales de los seres humanos, independientemente de su nacionalidad. Corte IDH. 


\section{ii. Lugar y condiciones de detención}

La Directiva establece que los migrantes deberán ser alojados en centros especializados (artículo 16), aunque excepcionalmente se permite su detención en centros penitenciarios. Sin perjuicio del nombre y finalidad del lugar, la Directiva parece haber desatendido un reciente informe que concluyó que en la amplia mayoría de los centros de internamiento en la UE regía un sistema carcelario que tendía a criminalizar a personas que no habían cometido crimen alguno, sino simplemente una infracción administrativa ${ }^{26}$.

\section{iii. Detención de niños y familias}

La Directiva permite detener a niños migrantes, con sus familias o solos, como último recurso y por el menor tiempo posible. También señala que el interés superior del niño deberá ser una "consideración de primer orden en el internamiento de los menores en espera de expulsión" (artículo 17). Sin embargo, organismos internacionales han indicado, como principio general, que los niños no acompañados nunca debieran ser detenidos ${ }^{27}$, que esta medida no podrá justificarse por su condición migratoria y, si excepcionalmente se dispone su detención, deben realizarse todos los esfuerzos para su liberación inmediata y posterior ubicación en alojamientos más apropiados ${ }^{28}$. El informe sobre los centros de detención en la UE sostuvo que la detención de niños "debería estar prohibida" y que el "interés superior del niño" no podría, "de ningún modo", suponer la privación de libertad, debiendo recurrir a medidas alternativas ${ }^{29}$.

\section{d. La no inaplicación de la Directiva: zonas de "no derecho"}

Los Estados pueden dejar sin aplicación la Directiva y desconocer las ya escasas garantías de ésta a los migrantes a quienes se les haya denegado la entrada, o hayan sido "interceptados o detenidos" por "cruce irregular de las fronteras exteriores", y que no hayan obtenido un permiso para permanecer (artículo 2). Será la legislación de cada Estado (más protectora o regresiva, según cada país) la que defina el nivel de dichas garantías. Esta normativa ignora que las situaciones que excluye afectan a quienes migran en condiciones de mayor vulnerabilidad y desprotección, y que restringe enormemente la libertad de circulación ${ }^{30}$. La exclusión de decenas de miles de personas frustra el objetivo invocado para justificar la formulación de la Directiva: brindar una protección común "mínima" a todas las personas.

Los más recientes mecanismos de control migratorio de la UE, como el proceso de externalización, han generado diversos cuestionamientos por la reducción de garantías y derechos que supone ${ }^{31}$.

El Efecto de las Reservas sobre la Entrada en Vigencia de la Convención Americana sobre Derechos Humanos. Opinión Consultiva OC-2/82 del 24 de septiembre de 1982. Serie A № 2, párr. 29. En igual sentido, Comisión Europea de Derechos Humanos, Caso Austria vs. Italia, Aplicación No 788/60, del 11/01/1961.

26 STEPS Consulting Social. Op. cit. nota 17, pp. 179, 180.

27 Grupo de Trabajo sobre Detención Arbitraria, visita al Reino Unido, E/CN.4/1999/63/Add.3, p. 37; Informe de la Relatora Especial de Naciones Unidas sobre Derechos Humanos de Migrantes, E/CN.4/2003/85, párr. 75.a.

28 Comité de los Derechos del Niño, Observación General № 6. Op. cit. nota 16, párr. 61.

29 STEPS Consulting Social. Op. cit. nota 17, pp. 22 y 210.

30 Las políticas restrictivas en países de destino, tránsito y origen no solamente impiden a millones de personas ingresar a otro territorio, sino también, progresivamente, salir del propio país.

31 "Externalización" es el proceso de desarrollo progresivo que, desde hace unos años, se ha implementado por parte de los Estados de la UE (tanto por separado como en el ámbito de la Unión) a través de diversos mecanismos dirigidos a involucrar a los países de origen y tránsito de migrantes hacia Europa, en la ejecución de los objetivos de la política europea de control de la migración irregular. Tratados bilaterales, multilaterales han ido conformando una serie de prácticas y marcos jurídicos a través de los cuales países fuera de la UE (especialmente, norte de África y Europa del este) llevan 
La Directiva, con la mencionada excepción, "legaliza" prácticas desprovistas de las garantías más elementales en las circunstancias más acuciantes. El ACNUR, que ya había solicitado la supresión del artículo 2 en $2005^{32}$, señaló que podría afectar el principio de no devolución, al ignorar que muchas personas están forzadas a ingresar de manera irregular ${ }^{33}$.

Ahora bien, en tanto los tratados obligan a los Estados a respetar y garantizar los derechos de todas las personas sujetas a su jurisdicción, incluidas las acciones que realicen fuera de su territorio (como los controles migratorios europeos en el norte de África) ${ }^{34}$, la Directiva no podría legitimar la no vigencia de garantías fundamentales para las personas interceptadas en dirección a Europa. El principio pro homine exigiría la aplicación prioritaria -frente a la Directiva- de otros instrumentos internacionales.

\section{Críticas desde Sudamérica: reacciones positivas y la necesidad de una política coherente}

Durante 2008 los países sudamericanos emitieron diversos pronunciamientos cuestionando la Directiva. EI MERCOSUR (Mercado Común del Sur) "deploró" su aprobación subrayando que no respeta la dignidad de migrantes en situación irregular; no es congruente con el derecho humanitario ni el DIDH; omite un enfoque comprehensivo de la migración; ignora el interés superior del niño, y vulnera el principio de reunificación familiar. Además afirmó que políticas migratorias restrictivas son ineficaces e incrementan la xenofobia, el racismo, el tráfico de migrantes y la trata de personas ${ }^{35}$.

La Declaración de la VIII Conferencia Sudamericana de Migraciones rechazó la Directiva y aludió a la consecuente criminalización de migrantes, y exhortó a los países más desarrollados a lidiar con las causas de las migraciones (pobreza y exclusión generadas por asimetrías económicas internacionales) y adoptar normativas compatibles con los derechos humanos ${ }^{36}$. Con motivo de las críticas a la Directiva en América Latina, la Organización de Estados Americanos encomendó a su Secretario General realizar una misión a la UE ${ }^{37}$. La UNASUR ${ }^{38}$ destacó la necesidad de

adelante una importante labor de control migratorio, según las pautas, intereses y objetivos definidos por autoridades de los países de la UE. Sobre la externalización del control migratorio hacia la UE, véanse: AA.VV. Frontera Sur. Nuevas políticas de gestión y externalización del control de la inmigración en Europa. Barcelona, Virus Editorial, 2008. RIJPMA, J. y CREMONA M. The Extra-Territorialisation of EU Migration Policies and the Rule of Law. Italia, European University Institute, Working Papers, Law 2007/01, 2007. WEINZIERL, R. The Demands of Human and EU fundamental Rights for the Protection of the European Unions External Borders. Berlin, German Institute for Human Rights, 2007. CERIANI, P. El control de la inmigración irregular en España a la luz de los tratados de derechos humanos: en las fronteras de la legitimidad. Universidad de Valencia, inédito, 2008.

32 ACNUR. Observaciones a la Propuesta de la Comisión Europea sobre la Directiva relativa a procedimientos y garantías para el retorno de nacionales de terceros países. 12/2005.

33 UNHCR position on the proposal for a Directive on common standards and procedures in Member States for returning illegally staying third-country nationals, 16/06/2008.

34 Sobre la aplicación extraterritorial de las obligaciones de derechos humanos, véase: GIL-BAZO, M. The practices of Mediterranean States in the Context of the European Unions Justice and Home Affairs External Dimension. The Safe Third Country concept revisited. International Journal of Refugee Law. 18: pp. 571-600, 2006. GONDEK, M. Extraterritorial application of the European Convention on Human Rights: Territorial focus in the age of globalization. Netherlands International Law Review. N ${ }^{\circ}$ 3: pp. 349-388, 2005. BORELLI, S. Casting light on the legal black hole: International Law and detentions abroad in the war on terror. International Review of the Red Cross. No 857: pp. 39-68, 2005.

35 Declaración de los países del MERCOSUR ante la "Directiva de retorno de la Unión Europea", Tucumán, 01/07/2008.

36 Montevideo, 19/09/2008.

37 Consejo Permanente OEA. Acción de la OEA sobre la Directiva de Retorno de la UE en materia migratoria, 26/06/2008, CP/RES. 938.

38 Unión de Naciones Suramericanas. 
garantizar la libre circulación de personas y un tratamiento digno a los migrantes ${ }^{39}$, y el Tribunal de la Comunidad Andina de Naciones invocó los estándares fijados por la Corte Interamericana para demandar la no discriminación con base en la nacionalidad o la condición migratoria de la persona ${ }^{40}$. Finalmente, mandatarios sudamericanos enviaron sendas cartas a la UE, cuestionando aspectos de la Directiva (el plazo de detención, el internamiento de niños) y la contradicción entre estas políticas y las medidas económicas y comerciales que contribuyen a incrementar la migración ${ }^{41}$.

Estas reacciones son signos positivos en la región, especialmente porque proponen políticas comprehensivas que incluyen las causas de la migración y la necesidad de garantizar los derechos de todas las personas migrantes. Pero estas repercusiones no guardan relación con las normas y políticas vigentes en diversos países sudamericanos. Esta contradicción se observa en dos aspectos: (1) la mantención de políticas que no garantizan los derechos de toda su población, incrementando la emigración, y (2) en Sudamérica aún existen leyes migratorias basadas en la doctrina de la seguridad nacional, adoptadas durante las dictaduras militares, que establecen un férreo control sobre la migración irregular que vulneran los derechos de los migrantes ${ }^{42}$.

Sin perjuicio de lo anterior, se han producido avances en la región. Las nuevas leyes de Argentina y Uruguay son un importante y positivo cambio, sin perjuicio de las tareas pendientes para su implementación efectiva y la plena garantía de los derechos de los migrantes en esos países. Varios Estados han realizado recientemente planes de regularización migratoria: el Programa Patria Grande (Argentina), los planes de Brasil y Chile para migrantes bolivianos y latinoamericanos, respectivamente, y el acuerdo bilateral entre Ecuador y Perú. También debe destacarse el giro de la nueva Constitución en la política migratoria ecuatoriana.

En cualquier caso, es preciso que los Estados sudamericanos adecuen sus políticas migratorias a los principios de derechos humanos y tengan en cuenta las causas de la migración. La coherencia política beneficiará el pleno goce de los derechos de migrantes e incrementará la legitimidad de los Estados para cuestionar la política migratoria en regiones como la UE.

\section{Reflexiones finales}

Hace unos diez años se advirtió que la identificación de derechos humanos con derechos de "ciudadanos de la Unión Europea" podía conducir a la violación del principio de igualdad y otros derechos fundamentales ${ }^{43}$. En 2003, la Directiva de la UE sobre reagrupación familiar materializó ese peligro ${ }^{44}$. Progresivamente, los organismos europeos han incorporado dispositivos de control

39 Declaración de la Unión de Naciones Suramericanas sobre la “Directiva de Retorno" de la Unión Europea, 04/07/2008.

40 Tribunal de Justicia de la Comunidad Andina, Carta al Presidente del TSJCE, Ref. 042-P-TJCA-2008, Quito, 25/06/2008

41 Cartas de los Presidentes de Bolivia y Ecuador, junio y julio de 2008, respectivamente.

42 Brasil (Ley 6.815, de 1980); Chile (Decreto 1094, de 1975, con penas de prisión); Ecuador (Decretos 1897 y 1899 , de 1971, aunque se reformaría en el corto plazo, dada la nueva Constitución). Hasta 2004, en Argentina regía la llamada "ley Videla", de 1981. La ley de Paraguay (№ 978, de 1996) prevé la prisión por reingreso no autorizado. A contrario sensu, Venezuela (ley 37.944, de 2004) prohíbe la detención de personas por razones migratorias, sea como sanción o medida cautelar.

43 CHUECA SANCHO, A. Los derechos fundamentales en la Unión Europea. Barcelona, Bosch, 1999, p. 57.

44 Directiva 2003/86/CE del Consejo Europeo sobre Reagrupación familiar de los nacionales de terceros Estados (del 22/09/2003). Al respecto véanse: MOLINER NAVARRO, R. El concepto de 'familia nuclear' en la Directiva europea 2003/86/CE sobre reagrupación familiar. Revista Aequalitas. № 15, Zaragoza, 2004. JOHN, A. Family reunification for migrants and refugees: a forgotten human right? A comparative analysis of family reunification under domestic law and 
migratorio, sobre visado ${ }^{45}$, operaciones conjuntas de retorno ${ }^{46}$, o sistemas de información y vigilancia fronteriza (Sistema de Información Schengen; Agencia FRONTEX). Aunque se incorporó el concepto de enfoque global de la migración ${ }^{47}$, que incluye la cooperación internacional, relaciones con terceros países y el nexo entre migración y desarrollo, la política está centrada en los objetivos e intereses de los Estados europeos y no en una gestión global del fenómeno, sus causas y consecuencias, desde un enfoque de derechos.

Para De Lucas la regresividad de la Directiva institucionaliza un estado de excepción que pone en jaque el estado de derecho, criminaliza la inmigración y echa por tierra una de las bases en que se asienta el proyecto de la UE: los derechos humanos ${ }^{48}$. El objetivo de la Directiva era fijar un mínimo común de garantías y derechos en los procesos de retorno. Después del análisis de esta normativa, se evidencia que el mínimo consensuado es notablemente regresivo. Si la Directiva se proponía armonizar prácticas, el resultado ha sido la codificación de las políticas más duras que existían en la región ${ }^{49}$ y la desatención de principios centrales del DIDH, como la progresividad, no regresividad o pro homine, y la no discriminación.

Una década atrás, Habermas planteaba que el tratamiento de los Estados europeos a la inmigración sería un test esencial sobre el futuro de Europa: "[...] ¿ ¿ [e]s que el chauvinismo con el que una mayoría en los países de nuestro tipo parece dispuesta a defender su bienestar, se endurecerá frente al exterior y se volverá represivo en el interior? [... $]^{\prime 50}$. Las políticas adoptadas por la UE y la mayoría de sus Estados, particularmente la Directiva de Retorno, parecen indicar que se ha escogido un camino restrictivo y desigual.

Las reacciones críticas de múltiples actores a nivel mundial pueden contribuir a reunir los consensos sociales y políticos que a futuro reviertan esta tendencia. En Sudamérica los Estados deben adoptar políticas centradas en un enfoque de derechos humanos y en la necesidad de un abordaje integral y comprehensivo a la migración. Una respuesta basada en estos principios fortalecerá y legitimará la demanda de los países sudamericanos. Algunos pasos se han dado en ese sentido, pero aún resta una enorme tarea por delante.

jurisprudence, international and regional instruments. ECHR case law and the EU 2003 family reunification Directive. Brasil, Universidad de Coimbra, 2004.

45 Reglamento n 574/1999 del Consejo, del 12/03/99, y sus reformas (la última, Reglamento 1932/2006 del Consejo, del 21/12/06).

46 Decisión 2004/573/CE del Consejo relativa a la organización de vuelos conjuntos para la expulsión, desde el territorio de dos o más Estados miembros, de nacionales de terceros países, del 29/04/2004.

47 Comisión Europea. El Planteamiento global sobre la migración un año después: Hacia una política global europea en materia de migración. COM (2006) 735, Bruselas, del 30/11/2006.

48 DE LUCAS, J. La UE ante la inmigración: balance de una esquizofrenia jurídica y política. Op. cit. nota 7; ZAMORA, J. Políticas de inmigración, ciudadanía y estado de excepción. Revista Arbor. Ciencia, Pensamiento y Cultura. № 713 : pp. 53-66, 2005.

49 ECRE (European Council on Refugees and Exiles). Returns Directive: Europe fails to uphold human rights. Press Release, Bruselas, del 18/06/2008.

50 HABERMAS, J. Más allá del Estado nacional. Madrid, Trotta, 1997, p. 119. 